\title{
Association of a Novel DNA Virus with the Grapevine Vein-Clearing and Vine Decline Syndrome
}

\author{
Yu Zhang, Kashmir Singh, Ravneet Kaur, and Wenping Qiu
}

First, second, third, and fourth authors: Center for Grapevine Biotechnology, William H. Darr School of Agriculture, Missouri State University, Mountain Grove 65711.

Current address of K. Singh: Department of Biotechnology, Panjab University, Chandigarh-160014, Punjab, India.

Current address of R. Kaur: Department of Biotechnology, Government College, Mohali, Punjab, India.

Accepted for publication 1 May 2011.

\begin{abstract}
Zhang, Y., Singh, K., Kaur, R., and Qiu, W. 2011. Association of a novel DNA virus with the grapevine vein-clearing and vine decline syndrome. Phytopathology 101:1081-1090.

A severe vein-clearing and vine decline syndrome has emerged on grapevines (Vitis vinifera) and hybrid grape cultivars in the Midwest region of the United States. The typical symptoms are translucent veinclearing on young leaves, short internodes and decline of vine vigor. Known viral pathogens of grapevines were not closely associated with the syndrome. To obtain a comprehensive profile of viruses in a diseased grapevine, small RNAs were enriched and two cDNA libraries were constructed from a symptomatic grapevine and a symptomless grapevine, respectively. Deep sequencing of the two cDNA libraries showed that the

most abundant viral small RNAs align with the genomes of viruses in the genus Badnavirus, the family Caulimoviridae. Amplification of the viral DNA by polymerase chain reaction allowed the assembly of the whole genome sequence of a grapevine DNA virus, which shared the highest homology with the Badnavirus sequences. This is the first report of a DNA virus in grapevines. The new DNA virus is closely associated with the vein-clearing symptom, and thus has been given a provisional name Grapevine vein clearing virus (GVCV). GVCV was detected in six grapevine cultivars showing vein-clearing and vine decline syndrome in Missouri, Illinois, and Indiana, suggesting its wide distribution in the Midwest region of the United States. Discovery of DNA viruses in grapevines merits further studies on their epidemics and economic impact on grape production worldwide.
\end{abstract}

Grapevines (Vitis vinifera L.) are commercially propagated by grafting of scion woods onto rootstocks or direct rooting of hard wood cuttings. These vegetative propagation practices promote the introduction of various viruses and viroids into a single vine. Frequent exchanges of source vines among nurseries worldwide and insect- or nematode-mediated transmission of viruses further accelerate the mixing of different viruses into individual vines. As a result, grapevine hosts the largest number of viruses, with 60 viruses and five viroids identified (17). The currently known grapevine viruses all have RNA genomes and no DNA virus has been reported (17). With the advent of new and more sensitive methods for detection of viruses, most grapevine viral diseases were found to be caused by mixed infection of multiple viruses in single vines $(2,13,16,19,22)$. The mixed infection of genetically diverse viruses is a challenge to the diagnostics and management of viruses on grapevines, and is becoming a serious threat to the healthy growth and profitability of grapevines in vineyards worldwide (24). Although currently known viruses play prominent roles in the pathogenesis of grapevine viral diseases, the potential role of unknown viruses in emerging grapevine diseases remains to be determined. Furthermore, the complexity of genetically diverse viruses and viroids in a single plant brings a new perspective on the understanding of the etiology of a disease and revises the conventional view on the correlation of a virus and a disease, particularly in the perennial woody crops.

Corresponding author: W. Qiu; E-mail address: WenpingQiu@ @issouristate.edu

* The $\boldsymbol{e}$-Xtra logo stands for "electronic extra" and indicates that the online version contains one supplemental table.

doi:10.1094/PHYTO-02-11-0034

(C) 2011 The American Phytopathological Society
A severe grapevine vein-clearing and vine decline syndrome has been observed in vineyards in the Midwest region of the United States in recent years and appears to be caused by a complex of viruses $(16,23)$. In those vines that have the syndrome, a narrow strip of chlorotic tissue forms along major or minor veins on the fully expanded leaves of young shoots that emerge from the primary buds in early spring. Chlorotic veins are translucent when the symptomatic leaves are held against sunlight. Young shoots develop short internodes with zigzag patterns. The leaves with vein-clearing symptoms develop into small, deformed mature leaves with expansion of chlorotic tissues, rolling back of leaf margins, or mosaic pattern of yellowing tissues interloped with green tissues. In the advanced stages, the affected vines become dwarfed and bear fewer fruit sets. The syndrome exhibits a broad range of foliar symptoms during the growing season, frequently resembling those caused by nepoviruses, which leads to a confusion of diagnosis. Translucent vein-clearing against sunlight, however, is the most striking and characteristic symptom that is useful for diagnosis. The syndrome has been found on 'Chardonnay', 'Chardonel', 'Cabernet Sauvignon', and 'Vidal Blanc' in Missouri; 'Cabernet Franc', 'Riesling', and 'Corot noir' in Indiana; and Chardonel in Illinois. It has caused significant reduction of vine vigor and yield in grape cultivars that possess major genetic background of $V$. vinifera and is becoming an increasing threat to grape and wine industries in the Midwest region.

When buds of diseased Chardonnay vines were grafted onto indicator grapevines 'Cabernet Franc', 'Baco Blanc,' and 'LN33', the grafted vines showed similar vein-clearing symptoms, suggesting that the causal pathogens can be transmitted by grafting (23). A previous investigation suggested a complex etiology of the vein-clearing and vine decline syndrome. Results 
from reverse-transcription polymerase chain reaction (RT-PCR) of 11 individual vines demonstrated that Grapevine fanleaf virus (GFLV), Tomato ringspot virus (ToRSV), and Grapevine rupestris stem pitting-associated virus (GRSPaV) were present in the affected vines but they were not closely associated with the symptoms (16). Therefore, it was proposed that unknown viruses were also associated with the disease (16).

One of the methods for discovering new viruses whose genome sequences are unknown is to extract double-stranded RNAs (dsRNAs), which are intermediate RNA molecules formed during the replication of viral RNA genomes, from infected samples. Deep sequencing of a dsRNA-derived cDNA library can identify viruses that have not been able to be detected by enzyme-linked immunosorbent assay (ELISA) or RT-PCR, techniques that require prior production of virus-specific antiserum or knowledge of virus-derived sequences (1). The dsRNA deep-sequencing method was recently employed in the investigation of viral pathogens that cause severe virus-like diseases in vineyards $(5,25)$. A second method is based on the RNA silencing (RNAi) phenomenon. RNAi is a cytoplasmic surveillance system for degradation of single-stranded RNA (ssRNA) and dsRNA molecules homologous to the inducer by using small-interfering RNAs (siRNAs) as a guide (6). Viruses are both inducers and targets of RNAi (6). As a result of RNAi, viral siRNAs accumulate abundantly in infected cells, and the composition of siRNAs reflects the progressive degradation of the target viral genome and the biogenesis of siRNAs (20). Viral siRNAs are derivatives of viral genomes in the cell, and high-throughput parallel sequencing of siRNAs has led to identification of novel viruses $(7,14,25)$ as well as commonly known viruses in symptomless plants that have extremely low titer of virions (4). Furthermore, enrichment and purification of small RNAs (sRNAs) greatly enhanced chances of discovering new viruses by reducing the complexity of sequences that are end products of antiviral RNAi (27). This unbiased sequencing strategy can also reveal the diversity, population structure, and genetic composition of viral genomes in a single plant.

In this study, we applied the deep-sequencing technology of siRNAs to identify viruses that are associated with the vein-clearing and vine decline syndrome. We discovered new viruses that have never been reported previously in grapevines. We selected one new virus for further investigation and sequenced its entire genome. The newly identified virus has a circular DNA genome of 7,753 bp. The predicted three open reading frames (ORFs) encode amino acid sequences that share the highest homology with those encoded by badnaviruses in the family Caulimoviridae. The new DNA virus is provisionally named Grapevine vein clearing virus (GVCV). The identification of novel DNA viruses in grapevine provides new opportunities for studying the etiology of emerging grapevine diseases and knowledge-based management of a severe vine decline disease that threatens grape production in the United States.

\section{MATERIALS AND METHODS}

Grapevines for the deep sequencing and for association study. Two individual Chardonel grapevines, LBC0903 and VFM411, were selected for the deep sequencing. The LBC0903 Chardonel was grown in a commercial vineyard (N: 38.57.810; W: 92.31.173) in Missouri, and showed a severe vein-clearing symptom on fully expanded leaves of young shoots. VFM411 was propagated from a $0.5-\mathrm{mm}$ microshoot tip after the Chardonel vine was treated under temperature of $37^{\circ} \mathrm{C}$ for $18 \mathrm{~h} /$ day and $22^{\circ} \mathrm{C}$ for $6 \mathrm{~h} /$ night for 1 month. Fully expanded young leaves were collected from new overwinter shoots of LBC0903 and VFM411.

Young shoots of symptomatic and nonsymptomatic vines were collected from two vineyards in Boone and Gasconade Counties,
M) (Chardonel, Chardonnay, and Vidal Blanc), three vineyards in Pike, Adams, and Jackson Counties, IL (Chardonel, Chardonnay, and Vidal Blanc), and several vineyards in Knox County, IN (Chardonel, Cabernet Franc, Riesling, 'Marquis', Corot noir, Vidal Blanc, and 'Melody') in June 2010. Selected vines from Missouri and Illinois vineyards were also propagated in a greenhouse for further study. Leaves were frozen in liquid nitrogen and stored at $-80^{\circ} \mathrm{C}$.

SRNA enrichment and sequencing of cDNA libraries. Total RNA was isolated following a protocol as described previously (8) and sRNAs were enriched by using the miRNAeasy kit (Qiagen). Briefly, $2 \mathrm{~g}$ of leaf tissue was ground in $25 \mathrm{ml}$ of extraction buffer (2\% hexadecyltrimethyl ammonium bromide, $2.5 \mathrm{M} \mathrm{NaCl}, 0.5 \mathrm{M}$ Tris, $50 \mathrm{mM}$ EDTA, $1 \%$ sodium dodecyl sulfate, $5 \% \beta$-mercaptoethanol, and $3 \%$ polyvinyl polypyrrolidone) and dispensed into $2-\mathrm{ml}$ centrifuge tubes for storage at $-80^{\circ} \mathrm{C}$. In total, $4 \mathrm{ml}$ of ground leaf tissue was centrifuged at $12,000 \times g$ for $20 \mathrm{~min}$ at $4^{\circ} \mathrm{C}$. Supernatant was extracted twice with an equal volume of chloroform. To the upper aqueous phase, 1.5 volumes of $100 \%$ ethanol was added and mixed thoroughly. The above samples were loaded onto miRNAeasy column from the miRNeasy kit (Qiagen) and centrifuged, and flow-through was discarded. The column was washed once with buffer provided in the kit and on-column DNase digestion for removing residual DNA was performed using the RNase-free DNase set (Qiagen). The column was washed again with wash buffer and clean RNA was eluted using RNase-free water.

RNA samples were sent to the Microarray and Genomic Analysis Core Facility, University of Utah, Salt Lake City, for preparation of the sRNA library and sequencing on the Illumina Genome Analyzer. sRNAs were separated on polyacrylamide gel by electrophoresis and RNA bands corresponding to the size range 20 to 30 nucleotides (nt) were purified from the gel by Illumina's Small RNA Sample Prep Kit. The 3' adapter (5'UCGUAUGCCGUCUUCUGCUUGUidT- $\left.3^{\prime}\right)$ and $5^{\prime}$ adapter $\left(5^{\prime}-\right.$ GUUCAGAGUUCUACAGUCCGACGAUC-3') were ligated to sRNAs in two steps. Adapters were designed to ligate specifically to sRNAs containing $5^{\prime}$ monophosphate and 3' hydroxyl ends that were found in the DCL-catalyzed products (12). Adapterligated sRNAs were converted to cDNA and then amplified in PCR. PCR-generated DNA libraries were subjected to the 36 cycled single-end sequencing using the Genome Analyzer II (Illumina).

Sequence analysis of sRNAs. After deep sequencing by the Solexa-Illumina platform, 11,305,926 and 11,307,006 single-end raw reads were acquired from LBC0903 and VFM411 samples, respectively. Adapter sequences attached to small cDNA sequences were removed by using Novoindex and Novolaign software (Novocraft Technologies, Selangor Darul Ehsan, Malaysia). Sequences $<16 \mathrm{nt}$ or $>28 \mathrm{nt}$ were excluded from further analysis. sRNA sequences were assembled into contigs of up to $1,000 \mathrm{nt}$ using short-sequence assembly programs. SSAKE v3-4 (26) programs were applied to assemble DNA sequences under user-defined parameters. SSAKE worked preferably with the parameter $-\mathrm{m}$ (minimum overlap) set at 16 and $-\mathrm{t}$ (end trimming) set to 2 .

A stand-alone BLAST program was installed on a laboratory computer. Genome sequences of viruses and viroids that were available on 15 February 2010 were downloaded from National Center for Biotechnology Information (NCBI) databases. Assembled contigs and singlet sequences were uploaded to search the virus and viroid databases by using BLASTN and BLASTX. Coverage and distribution of virus-specific sRNAs was determined in the Mapping and Assembly with Qualities program (MAQ) (http://maq.sourceforge.net) (15) using the easyrun script under default parameters. Only those sequences with the highest $e$ value and that matched with virus-specific sequences were selected for further analysis. 
RT-PCR and PCR. Total RNA was isolated and treated with DNase as described above. cDNA was synthesized by Superscript III RT using random hexamers following the manufacturer's instructions (Invitrogen, Carlsbad, CA). Resultant cDNA was used as template for PCR amplification.

Total DNA was extracted from $100 \mathrm{mg}$ of young leaf tissue by using Qiagen DNeasy Plant Mini Kit (Qiagen). At final step, DNA was eluted twice, each time with $50 \mu$ l of sterilized $\mathrm{d}_{2} \mathrm{O}$. For each PCR reaction, $50 \mathrm{ng}$ of DNA was added.

For PCR using the primer set GVCV-F1 (5'-CACGTTTC AAAGAAAGATGGAC-3') and GVCV-R1 (5'-ATCCKTCCAT GCAWCCGTCAG- $3^{\prime}$ ), the program was performed with an initial denaturation at $94^{\circ} \mathrm{C}$ for $1 \mathrm{~min}$; followed by 35 cycles of denaturation at $94^{\circ} \mathrm{C}$ for $30 \mathrm{~s}$, annealing at $52^{\circ} \mathrm{C}$ for $40 \mathrm{~s}$, and extension at $72^{\circ} \mathrm{C}$ for $1 \mathrm{~min}$; and a final extension at $72^{\circ} \mathrm{C}$ for 7 min. For PCR using the primer set GVCV6666F $\left(5^{\prime}\right.$-ACTT CCTCCACCCCACGCAGTTATC-3') and GVCV1514R (5'-GCA CGAGGCAACTCAGTGGTCT-3'), initial denaturation was at $94^{\circ} \mathrm{C}$ for 2 min followed by 35 cycles of denaturation at $94^{\circ} \mathrm{C}$ for $30 \mathrm{~s}$, annealing at $55^{\circ} \mathrm{C}$ for $40 \mathrm{~s}$, and extension at $68^{\circ} \mathrm{C}$ for $4 \mathrm{~min}$. A final extension at $68^{\circ} \mathrm{C}$ for $10 \mathrm{~min}$ was included. PCR products were inspected on a $1.2 \%$ agarose gel through electrophoresis. PCR amplicons were cloned into pCR8/GW/TOPO-TA vector (Invitrogen). Recombinant plasmids with inserts were isolated and sequenced. DNA sequencing was performed in the Nevada Genomics Center, University of Nevada (Reno).

Cloning of GVCV-specific fragments and sequencing. In order to acquire the full-length GVCV genome, three sets of primers were designed to amply the fragments from the grapevine LBC0903 with overlapping regions to ensure that three amplified fragments were derived from the same viral DNA and also for assembling the whole viral genome. Three recombinant plasmids were constructed. Plasmid 1915-4162 contained the DNA fragment of 1,915 to $4,162 \mathrm{nt}$ that was amplified using primers GVCV1915F (5'-AGAATACAAGTGCTACACCGA-3') and GVCV4162R (5'-CATGAGAGTCATGAGGTTTAC-3'); plasmid 4142-6721 contained the DNA fragment of 4,142 to 6,721 nt that was amplified using primer set GCVC4142F (5'-GTAAAC CTCATGACTCTCATG-3') and GVCV-R1; and plasmid 61921935 contains the fragment of 6,192 to 1,935 nt that was amplified using primers GVCV-F1 and GVCV1935R (5'-TCGG TGTAGCACTTGTATTCT-3'). Primers GVCV1915F and GVCV $1935 \mathrm{R}$ as well as GVCV 4142F and GVCV4162R are complementary at the same location.

PCR was performed using Platinum Taq DNA Polymerase High Fidelity (Invitrogen). DNA fragments were isolated from a $1 \%$ agarose gel and cloned into pCR8/GW/TOPO vector following the manufacturer's instructions (Invitrogen). Positive colonies that contained recombinant plasmids were confirmed by colony PCR using the specific primers. Bacteria of individual colonies were cultured in $5 \mathrm{ml}$ of Luria broth medium containing spectinomycin at a concentration of $100 \mu \mathrm{g} / \mathrm{ml}$ at $37^{\circ} \mathrm{C}$ overnight. Plasmid DNA was purified using a QIAprep Spin Miniprep Kit and eluted in $50 \mu \mathrm{l}$ of $\mathrm{dH}_{2} \mathrm{O}$. Recombinant plasmid DNA was verified to contain the target fragment before it was sent out for sequencing.

The sequencing of DNA fragments was done at Nevada Genomics Center, University of Nevada (Reno). M13 primers and GW primers (in the pCR 8/GW/TOPO TA cloning kit) (Invitrogen) were used in the first sequencing reactions, and subsequent sequences were obtained by primer walking from both forward and backward directions so that each base pair was sequenced at least twice. Additional sequencing was conducted if any ambiguous nucleotides were found between both forward and backward sequences. Contigs were achieved in the Contig Assemble Module of the Vector NTI 8.0 (Invitrogen). The whole genome sequence of GVCV was assembled by combining the sequences of three overlapping fragments.
Phylogenetic analysis. The sequences of the type species of each genus and the 10 Badnavirus spp. in the family Caulimoviridae were retrieved from the NCBI (http://www. ncbi.nlm.nih.gov). Alignment and phylogenetic analysis were conducted in the MEGA 4 package (http://www.megasoftware.net). Phylogenetic trees were generated using neighborjoining method in MEGA4. The amino acids in the RT region were selected for the analysis of phylogenetic relationship among the six genera. Viruses, GenBank accession numbers, and amino acid sequences selected were Petunia vein clearing virus (U95208, D1412-G1588 in ORF I), Cassava vein mosaic virus (CVMV) (U20341, Y243-G410 of ORF III), Commelina yellow mottle virus (ComYMV) (X52938, K1429-G1612 of ORF III), Rice tungro bacilliform virus (X57924, K1238-G1387 of ORF III), Cauliflower mosaic virus (V00140, K273-I452 of ORF V), Soybean chlorotic mottle virus (X15828, G230-I411 of ORF V), and GVCV (G1452-I1638 of ORF III).

The conserved region of RT and RNase H in GVCV (S1523R1860 of ORF III) was selected for analysis of its relationship to other closely related badnaviruses. Viruses, GenBank accession numbers, and amino acid sequences selected were Banana streak virus-AcYun (DQ092436, S1396-R1733 of ORF III), Banana streak virus-Vietnam (AY750155, S1394-R1731 of ORF III), Kalanchoe top-spotting virus (AY180137, S1427-R1762 of ORF III), Taro bacilliform virus (TaBV) (AF357836, S1386-R1723 of ORF III), Banana streak OL virus (AJ002234, S1334-R1671 of ORF III), Cacao swollen shoot virus (L14546, S1379-R1716 of ORF III), Citrus yellow mosaic virus (AF347695, S1494-R1831 of ORF III), Sugarcane bacilliform virus isolate Batavia D (FJ439817, S1311-R1647 ORF III), and ComYMV (X52938, S1500-R1837 ORF III).

\section{RESULTS}

SRNA sequences of multiple viruses were discovered in the symptomatic Chardonel vine. We enriched the sRNA molecules from an individual grapevine, LBC0903, that exhibited a severe vein-clearing and vine decline syndrome and one grapevine, VFM411, that was generated from the tissue culturing of microshoot tips after the vine was subject to thermotherapy. Two cDNA libraries were constructed from the enriched sRNAs and the deep sequencing of the cDNA libraries was performed by Illumina's GAII sequencing platform. After deep sequencing, $11,305,926$ and 11,307,006 single-end raw reads were acquired from LBC0903 and VFM411 samples, respectively. After removing the reads $<16 \mathrm{nt}$ and $>28 \mathrm{nt}, 8,885,626$ and 9,800,815 reads were left for LBC0903 and VFM411 samples, respectively, and used in the assembly step. The SSAKE assembling produced 42,560 and 14,061 contigs in the size range of 35 to $600 \mathrm{nt}$ for LBC0903 and VFM411, respectively. The sequences that were not assembled into contigs were considered singletons $(1,454,664$ for LBC0903 and 12,781 for VFM411). The contig and singleton sequences were subject to BLAST analysis against nonredundant viral sequence databases that were retrieved from NCBI. Only those sequences that matched with virus-specific sequences with the highest $e$ value were selected for further analysis. BLAST results revealed the presence of multiple viruses that belong to different families. In total, 27 viruses were selected for further analysis based on the $e$ value and number of hits (Table 1). Each reference genome of the 27 viruses was selected on the basis of the highest number of hits by siRNAs against that genome in BLAST analysis. Genome sequences of the 27 selected viruses were retrieved from the NCBI database and aligned with viral small (vs)RNAs in the reassembly studies using the MAQ assembler, where each vsRNA read was assigned to a unique genome position. In each of the 27 viruses analyzed, the number of BLAST hits matching with virus-specific sequences was considerably lower in VFM411 than in LBC0903, which was 
further verified by MAQ analysis (Table 1). For example, there are 35,843 vsRNA reads mapped to the genus Badnavirus in the family Caulimoviridae in the symptomatic LBC0903 sample. In contrast, only 20 vsRNA reads were found to be aligned with the genomes of badnaviruses in the symptomless VFM411 (Table 1). Out of the total number of vsRNA reads, $57 \%$ belonged to the genera Badnavirus (99\%) and Caulimovirus (1\%) in the family Caulimoviridae (Table 1).

Characterization of a putative Badnavirus genome. Because the vsRNAs homologous to badnaviruses are the most abundant in the symptomatic LBC0903 grapevine, we focused on the characterization of one putative badnavirus. We designed primers from the highly conserved genomic regions to which multiple vsRNAs were mapped. We amplified three large DNA fragments with overlapping regions by PCR, cloned them into plasmids, and sequenced the virus-specific DNA fragments from both directions by the primer-walking strategy. Upon assembling the entire genome, we also amplified additional fragments by primers that anneal to two borders outside the overlapping regions and sequenced them to ensure that overlapping regions did, indeed, share identical nucleotides.

The assembled GVCV genome has a size of 7,753 bp. Following the conventional numbering for the genome of a plant pararetrovirus, the first nucleotide of the GVCV genome starts at 5'-TGGTATCAGAGCTCCAG on the plus strand, which is complementary to the $3^{\prime}$-end 12 nucleotides of the plant tRNA ${ }^{\text {met }}$ consensus sequence (3'-ACCAUAGUCUCGGUCCAA-5') (Fig. 1). Three ORFs were identified on the plus-strand of the GVCV genome that potentially encode three proteins with a molecular mass of $>10 \mathrm{kDa}$ (Fig. 1; Table 2). The amino acid sequences predicted from ORF1, -2 , and -3 are similar to those counterparts found on the genome of ComYMV (18), the type member in the genus Badnavirus. To provide further evidence that GVCV can be provisionally assigned to the genus Badnavirus based on the sequence similarity, we performed phylogenetic analysis of GVCV with type species of six genera Caulimovirus, Soymovirus, Badnavirus, Tungrovirus, Cavemovirus, and Petuvirus in the family Caulimoviridae using the amino acid sequences of RT region. The analysis result showed that GVCV and Com YMV are most closely related and should be assigned to the same clade in the genus Badnavirus (Fig. 2A).

Because differences in nucleotides encoding the polymerase (RT and Rnase $\mathrm{H}$ ) are designated as one of the criteria in species classification of the genus Badnavirus, we performed nucleotide sequence analysis and found that the uncorrected nucleotide distance of GVCV coding region for RT and Rnase $\mathrm{H}$ with other

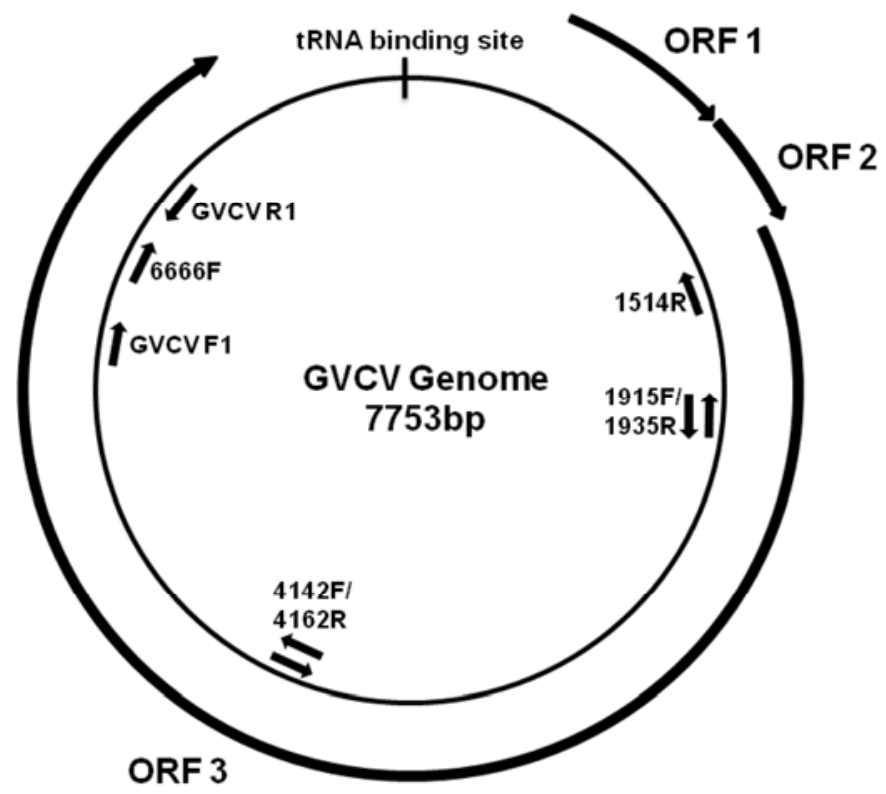

Fig. 1. Genomic organization of the provisional Grapevine vein clearing virus (GVCV). Positions of three predicted open reading frames (ORFs) and primers used in the detection of GVCV and cloning of the genomic fragments are indicated on the circular GVCV genome. The tRNA binding site, which is complementary to the consensus sequence of plant tRNA ${ }^{\text {met }}$, is considered as starting site of the complete genome.

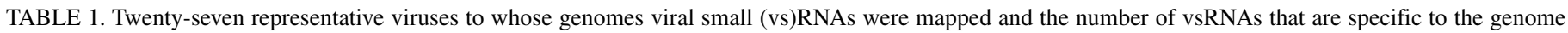
of a particular virus ${ }^{\mathrm{a}}$

\begin{tabular}{|c|c|c|c|c|}
\hline Virus & Genus & Family & VFM-411 & LBC0903 \\
\hline Dioscorea bacilliform virus & Badnavirus & Caulimoviridae & 5 & 15,236 \\
\hline Taro bacilliform virus & Badnavirus & Caulimoviridae & 0 & 3,550 \\
\hline Cycad leaf necrosis virus & Badnavirus & Caulimoviridae & 3 & 6,518 \\
\hline Dracaena mottle virus & Badnavirus & Caulimoviridae & 10 & 4,457 \\
\hline Sweetpotato badnavirus $B$ & Badnavirus & Caulimoviridae & 0 & 4,528 \\
\hline Strawberry vein banding virus & Badnavirus & Caulimoviridae & 2 & 1,554 \\
\hline Lamium leaf distortion associated virus & Caulimovirus & Caulimoviridae & 11 & 407 \\
\hline Potato leaf roll virus & Polerovirus & Luteoviridae & 0 & 11,679 \\
\hline Sugarcane yellow leaf virus & Luteovirus & Luteoviridae & 1 & 639 \\
\hline Tobacco leaf curl virus & Gemini virus & Geminiviridae & 108 & 521 \\
\hline Orchid fleck virus & Rhabdovirus & Rhabdoviridae & 0 & 860 \\
\hline Soil borne wheat mosaic virus & Furovirus & Virgaviridae & 2 & 6,199 \\
\hline Grapevine rootstock stem lesion associated virus & Closterovirus & Closteroviridae & 1 & 285 \\
\hline Carrot yellow leaf virus & Closterovirus & Closteroviridae & 1 & 1,702 \\
\hline Grapevine leafroll-associated virus 2 & Closterovirus & Closteroviridae & 83 & 984 \\
\hline Grapevine leafroll-associated virus 10 & Ampelovirus & Closteroviridae & 2 & 446 \\
\hline Tomato infectious chlorosis virus & Crinivirus & Closteroviridae & 0 & 380 \\
\hline Grapevine virus $A$ & Vitivirus & Betaflexiviridae & 0 & 782 \\
\hline Grapevine virus $B$ & Vitivirus & Betaflexiviridae & 0 & 156 \\
\hline Grapevine virus $E$ & Vitivirus & Betaflexiviridae & 1 & 227 \\
\hline Butterbur mosaic virus & Carlavirus & Betaflexiviridae & 4 & 478 \\
\hline Grapevine syrah virus 1 & Marafivirus & Tymoviridae & 0 & 198 \\
\hline Grapevine fleck virus & Maculavirus & Tymoviridae & 100 & 350 \\
\hline Tomato spotted wilt virus & Tospovirus & Bunyaviridae & 36 & 329 \\
\hline Grapevine fanleaf virus & Nepovirus & Secoviridae & 0 & 1,055 \\
\hline Grapevine chrome mosaic virus & Nepovirus & Secoviridae & 2 & 241 \\
\hline Rubus chlorotic mottle virus & Sobemovirus & Sobemovirus & 1 & 90 \\
\hline
\end{tabular}

a Virus families in bold have not been reported previously in grapevines. 
badnaviruses is $<80 \%$ of the nucleotide identity threshold value for delimitation of strains and species of the genus Badnavirus (10). Phylogenetic analysis based on the amino acid sequences consisting of RT and RNase $\mathrm{H}$ active sites between GVCV and 10 other badnaviruses revealed that GVCV is most closely related to TaBV (Fig. 2B).

GVCV is closely associated with vein-clearing symptom. To investigate whether the newly identified GVCV is consistently present in the vines with the vein-clearing symptom, we extracted total RNA from six individual grapevines that were collected from a commercial vineyard and converted RNA to cDNA after degradation of DNA with DNase. We also included reactions without addition of RT during the cDNA synthesis as a negative reaction control. Results of the RT-PCR assays using the primer set GVCV-F1 and GVCV-R1 demonstrated that the GVCV-specific fragment of 530 bp was present in four vinesLBC0902, LBC0903, LBC1001, and LBC1003-while absent in vines LBC0901 and LBC1002 (Fig. 3A). Sequencing of the 530-bp DNA fragment confirmed that it shared identical sequences with the corresponding fragment on the GVCV genome from the symptomatic LBC0903 sample. Because no DNA fragments were detected in the reactions in which no RT was added (Fig. 3A), the results indicated that the 530-bp fragment was amplified from a cDNA template instead of genomic DNA and supported that GVCV-specific transcripts are present in virusinfected cells.

In addition, we extracted genomic DNA from the six grapevine samples and subjected the grapevine genomic DNA to PCR. In this experiment, we designed another pair of primers (GVCV6666F and GVCV1514R) based on the newly sequenced GVCV genome. The results from PCR using genomic DNA as template were in agreement with the RT-PCR results. A GVCV-specific fragment of $2,623 \mathrm{bp}$ was present in all four samples that exhibited vein-clearing symptoms on young leaves (LBC0902, LBC0903, LBC1001, and LBC1003) but not in the asymptomatic samples LBC0901 and LBC1002 (Fig. 3B and C). These results strongly suggested that GVCV is present as a DNA form in the symptomatic grapevines.

In a previous project in our laboratory, we grafted two buds of Chardonnay vines with translucent vein-clearing symptoms onto asymptomatic Chardonnay and Cabernet Franc vines and found that the grafted vines developed similar vein-clearing symptom (23). We applied the RT-PCR assay to these samples and detected GVCV in the original symptomatic Chardonnay and also in the grafted Chardonnay and Cabernet Franc (Fig. 4). These results showed that GVCV is transmissible by bud grafting, and provided further evidence that GVCV is associated with the vein-clearing symptom.

GVCV is identified in grapevines in three states. A translucent vein-clearing symptom was first observed on Chardonnay in a commercial vineyard in Missouri in 2004 (23); similar symptoms have since been observed on other grape cultivars. Young leaves from four Chardonel vines and two Vidal Blanc vines with the vein-clearing symptom were collected from another commercial vineyard in Missouri. RT-PCR assays were conducted on these samples using the primer set GVCV-F1 and GVCV-R1. The results indicated that the GVCV-specific fragment of $530 \mathrm{bp}$ was present also in the Vidal Blanc vine (SHV0905) with the vein-clearing symptom (Fig. 5A and B). To examine whether GVCV was present in other grape cultivars in Midwest states beyond Missouri, we surveyed vineyards in Illinois and Indiana. RT-PCR assays were conducted on leaf samples that were collected from Chardonel, Vidal Blanc, and Chardonnay vines in three Illinois vineyards in 2010. GVCV was found in two Chardonel, one Vidal Blanc, and one Chardonnay vine in Illinois, and

A

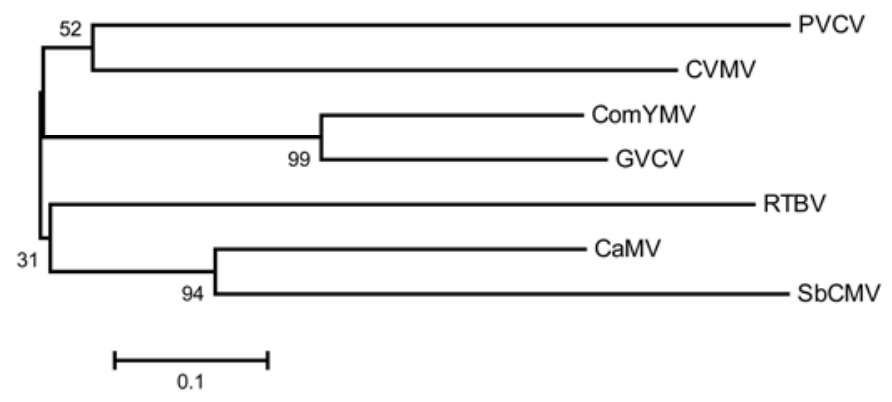

B
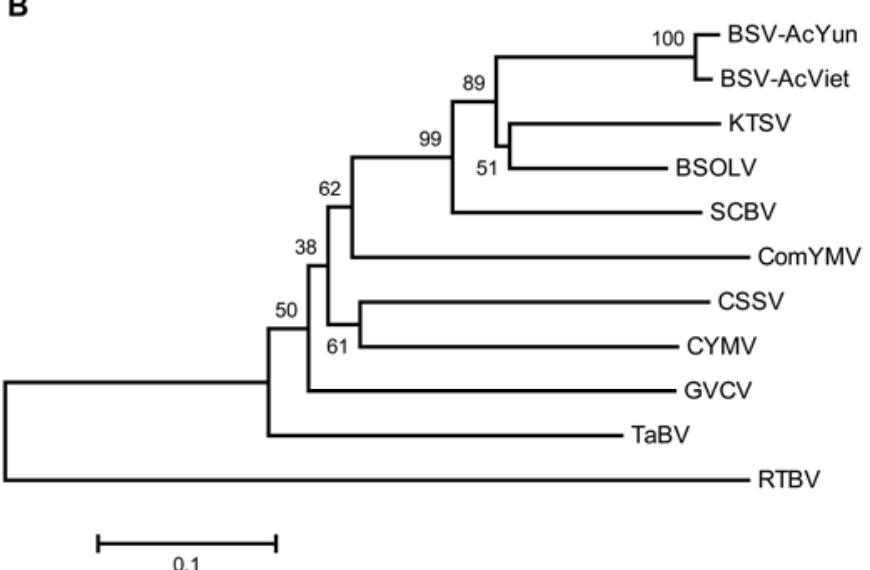

Fig. 2. Phylogenetic analyses for putative classification of Grapevine vein clearing virus (GVCV) in the family Caulimoviridae. A, Phylogenetic tree showing the relationship of GVCV with type species of six genera in the family: Cauliflower mosaic virus (CaMV) of Caulimovirus, Soybean chlorotic mottle virus (SbCMV) of Soymovirus, Commelina yellow mottle virus (ComYMV) of Badnavirus, Rice tungro bacilliform virus (RTBV) of Tungrovirus, Cassava vein mosaic virus (CVMV) of Cavemovirus, and Petunia vein clearing virus (PVCV) of Petuvirus. The tree was constructed using reversetranscriptase amino acids. B, Phylogenetic analysis of GVCV and other closely related Badnavirus spp. (including Banana streak virus-AcYun [BSVAcYun], Banana streak virus-Vietnam [BSV-AcViet], Kalanchoe top-spotting virus [KTSV], Banana streak OL virus [BSOLV], Sugarcane bacilliform virus isolate Batavia D [SCBV], Cacao swollen shoot virus [CSSV], Citrus yellow mosaic virus [CYMV], and Taro bacilliform virus [TaBV]) using the conserved region of reverse transcriptase and RNase $\mathrm{H}$ amino acid sequences. The percentage of replicate trees in the bootstrap test (1,000 replicates) is shown next to the branches. The bar indicates the evolutionary distance as the number of amino acid substitutions per site. Phylogenetic trees were generated using neighbor-joining method in MEGA4.

TABLE 2. Predicted open reading frames (ORFs) on the plus-strand of Grapevine vein clearing virus (GVCV)

\begin{tabular}{|c|c|c|c|c|c|c|}
\hline ORF & First nucleotide & Last nucleotide ${ }^{a}$ & Size (nucleotides) & Amino acids & Molecular mass (kDa) & Active sites ${ }^{b}$ \\
\hline 1 & 485 & 1,111 & 624 & 208 & 24.2 & Unknown \\
\hline 2 & 1,112 & 1,495 & 381 & 127 & 14.3 & Unknown \\
\hline 3 & 1,495 & 7,320 & 5,823 & 1,941 & 219.5 & $\begin{array}{l}\text { MP motif, CP, } \\
\text { RT, RNase H }\end{array}$ \\
\hline
\end{tabular}

a Including the stop codon.

b MP: movement protein; CP: coat protein; RT: reverse transcriptase. 


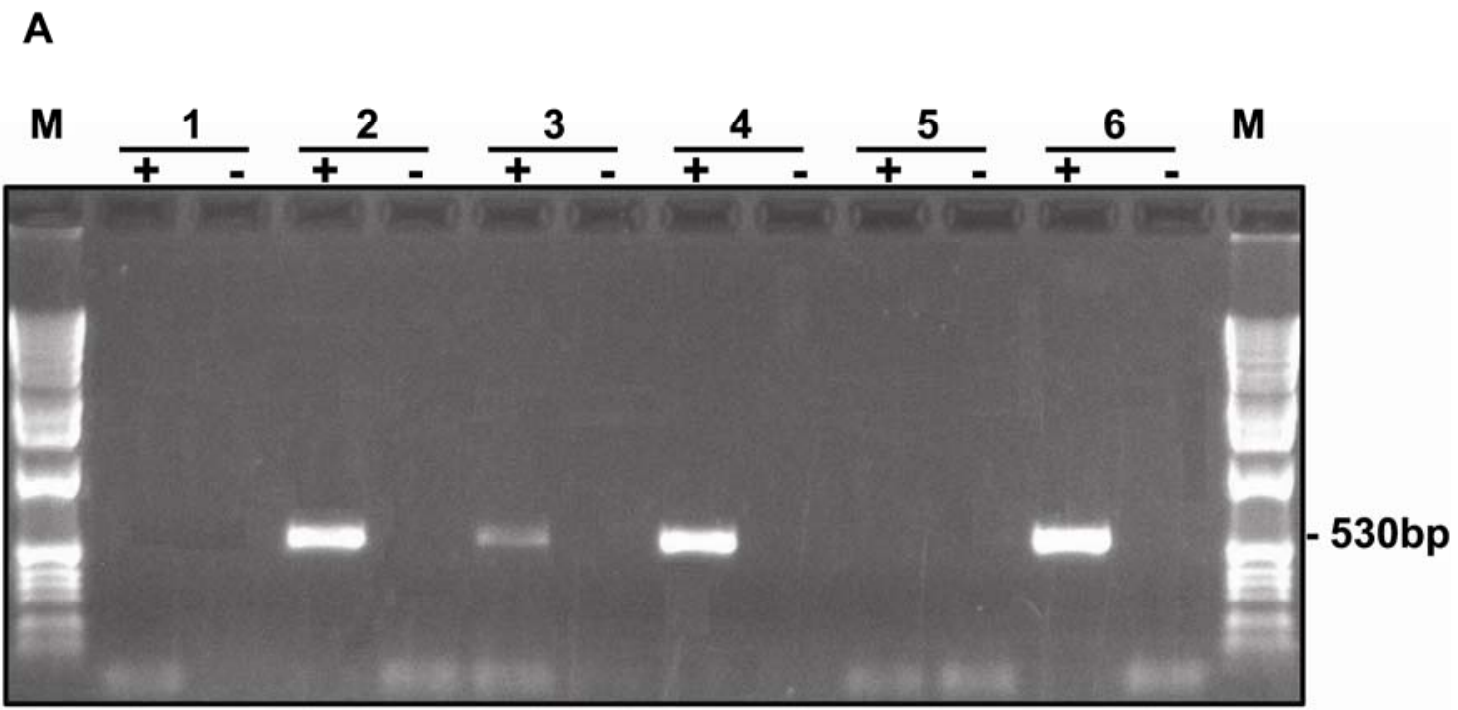

B

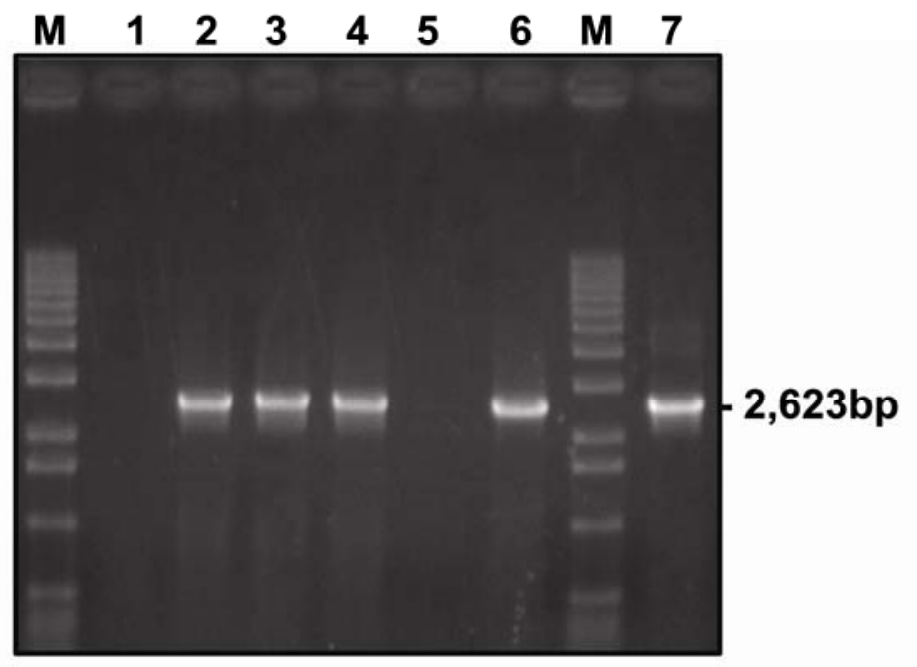

C
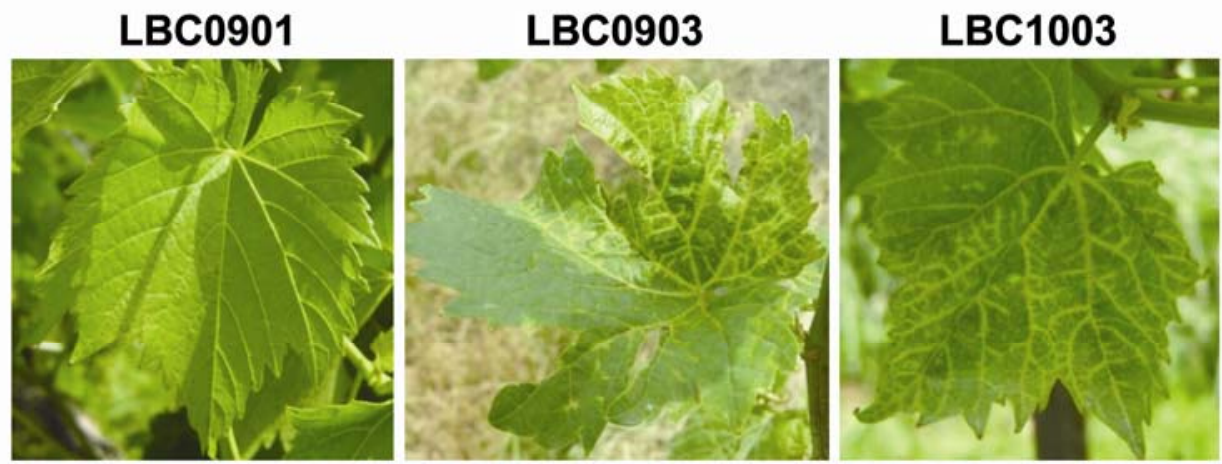

Fig. 3. Association of Grapevine vein clearing virus (GVCV) with the vein-clearing symptom on 'Chardonel' vines in a commercial vineyard. A, Presence of GVCV-specific fragment of $530 \mathrm{bp}$ in the symptomatic vines. Reverse-transcription polymerase chain reaction (PCR) was performed by using primer pair GVCVR1 and GVCV-F1. Plus sign denotes the reaction with cDNA as template; minus sign indicates the reaction in which no reverse transcriptase was added in the cDNA reaction, which was used as a negative control for ruling out contamination of genomic DNA. Lane 1, asymptomatic LBC0901; lane 2, LBC0902; lane 3, LBC0903; lane 4, LBC1001; lane 5, LBC1002; lane 6, LBC1003; lane M, size markers of DNA fragments in base pairs. B, Detection of GVCV-specific fragment of 2,623 bp to verify the presence of GVCV in the symptomatic vines. PCR was performed by using genomic DNA as template and primer pair GVCV6666F and GVCV1514R. Lanes 1 to 6 are the same samples as in A; lane 7, recombinant plasmid containing the GVCV fragment as positive control in PCR. C, Typical veinclearing symptom as represented on LBC0903 and LBC1003, while LBC0901 did not show symptoms. Photos were taken from a commercial Chardonel vineyard on 19 June 2010. 


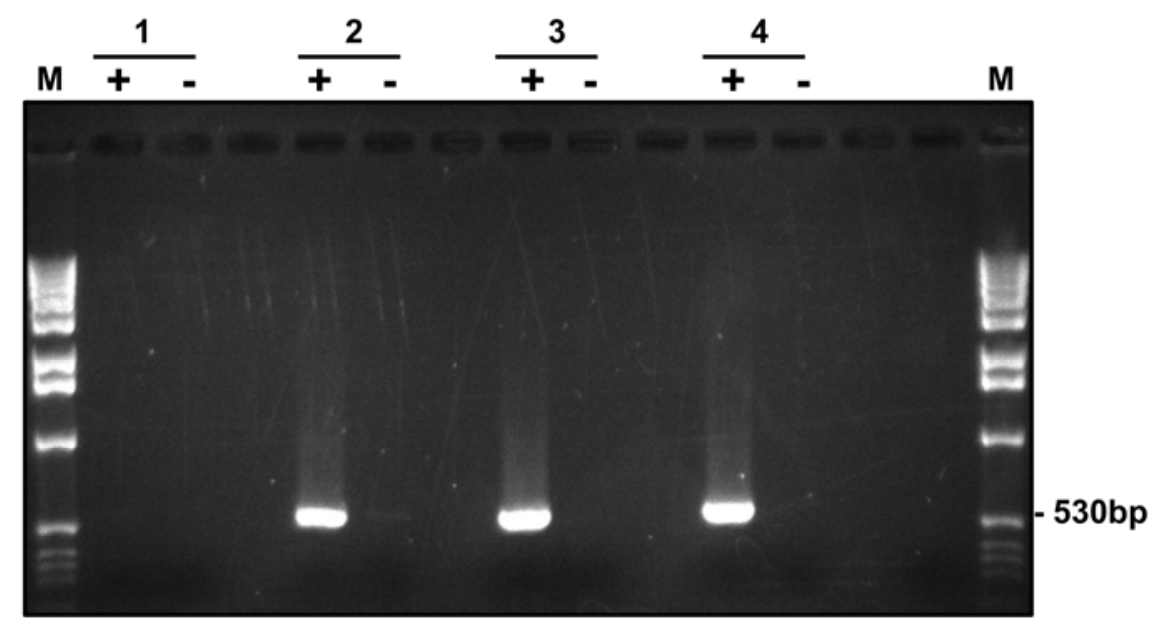

Fig. 4. Presence of Grapevine vein clearing virus (GVCV)-specific DNA products of 530 bp in the grafted 'Cabernet Franc' and 'Chardonnay' as well as in the symptomatic Chardonnay vine. Reverse-transcription polymerase chain reaction was performed by using primer pair GVCV-F1 and GVCV-R1. Lane 1, mockgrafted asymptomatic Chardonnay vine; lane 2, GVCV-grafted Cabernet Franc vine; lane 3, original GVCV-infected Chardonnay vine that shows translucent veinclearing symptom; lane 4, GVCV-grafted Chardonnay vine. Plus sign denotes the reaction with cDNA as template and minus sign indicates the reaction in which no reverse transcriptase was added in the cDNA reaction, which was used as a negative control for ruling out contamination of genomic DNA. Lane M, size markers of DNA fragments in base pairs.

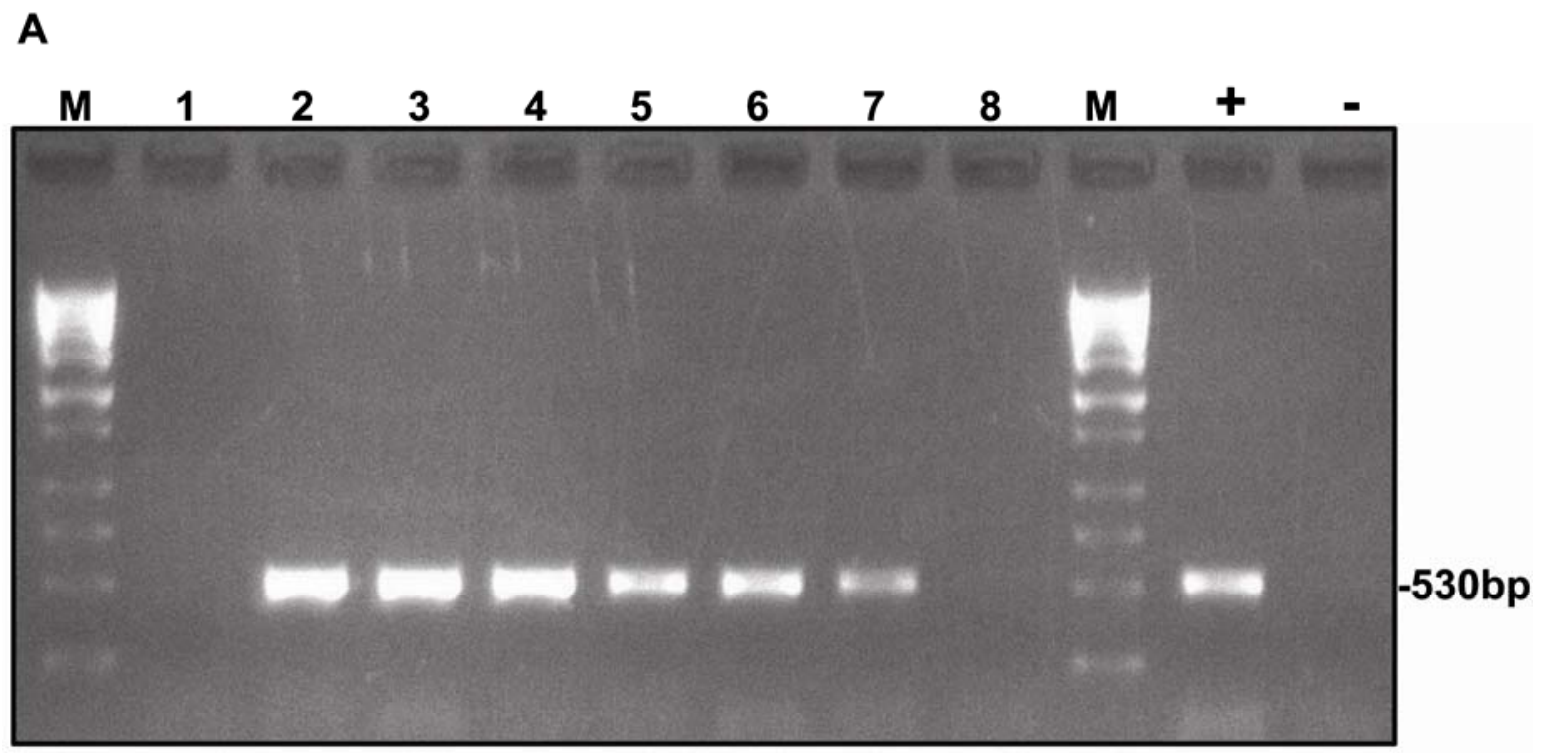

B

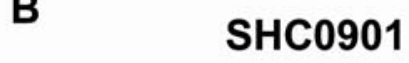

SHV0905
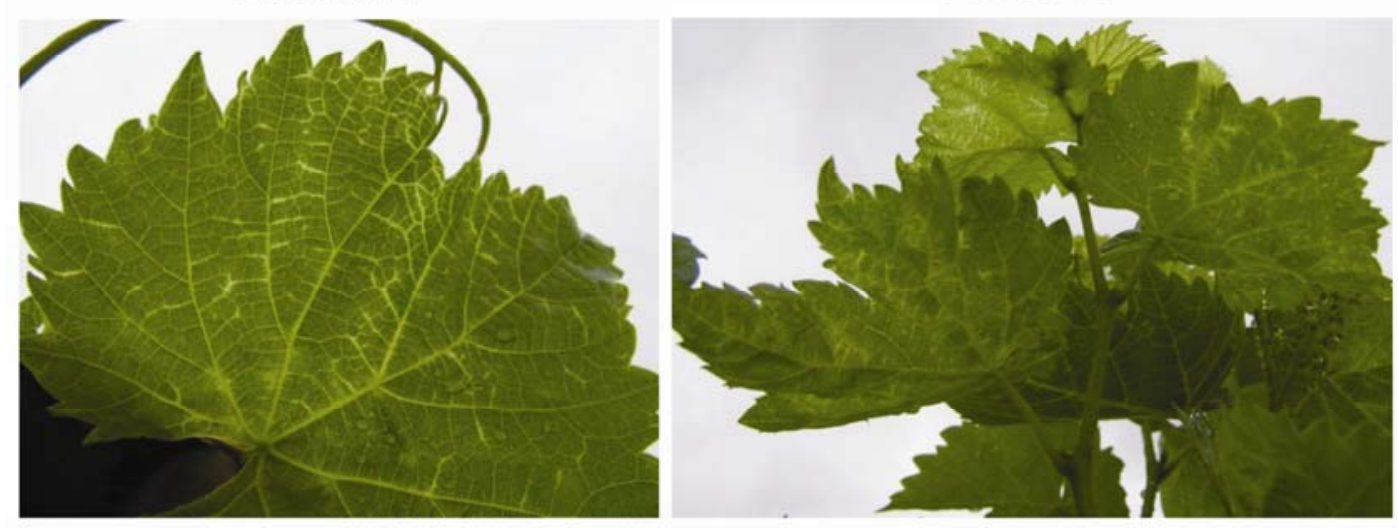

Fig. 5. Association of Grapevine vein clearing virus (GVCV) with the vein-clearing symptom on 'Chardonel' and 'Vidal Blanc' vines in a commercial vineyard. A, Presence of GVCV-specific fragment of $530 \mathrm{bp}$ in the symptomatic vines. Reverse-transcription polymerase chain reaction was performed by using primer pair GVCV-R1 and GVCV-F1. Lane 1, LBC0901; lane 2, SHC0901; lane 3, SHC0902; lane 4, SHC0903; lane 5, SHC0904; lane 6, SHV0905; lane 7, SHV0906; lane 8, SJC0901. Plus sign denotes positive control using LBC0903 sample; minus sign indicates negative control; lane M, size markers of DNA fragments in base pairs. B, Characteristic vein-clearing symptom showing on SHC0901 and SHV0905. Photos were taken from a commercial vineyard on 3 June 2009. 
two samples were negative while symptoms were yet to be confirmed (Table 3). PCR assays using genomic DNA as template were performed on 10 grapevines, including Cabernet Franc, Riesling, Marquis, Chardonel, Corot noir, Vidal Blanc, and Melody, that were collected in Indiana in 2010. GVCV was discovered in Cabernet Franc, Riesling, Chardonel, and Corot noir but not in Marquis, Vidal Blanc, and Melody in Indiana (Table 3). These results demonstrated that GVCV is present in six grape cultivars in three states in the Midwest region of the United States, and that there is a close correlation between the presence of GVCV and vein-clearing symptoms on these cultivars.

\section{DISCUSSION}

By applying deep sequencing of sRNAs enriched from symptomatic LBC0903 and asymptomatic VFM411 grapevine, we profiled a large number of vsRNAs that share identical nucleotide sequences with the genomes of 27 plant viruses (Table 1). The most abundant vsRNAs are derived from badnaviruses (Table 1). Focused investigation identified a DNA virus in grapevine for the first time, and the genome sequences of the new grapevine DNA virus were obtained by sequencing the fragments in both directions. The whole genome was assembled from the sequences of three DNA fragments that were amplified from the LBC0903 grapevine. Sequencing analysis showed that they share identical nucleotides in the overlapped regions, indicating that the three PCR-amplified DNA fragments were derived from the same circular genome. The whole genome sequences and predicted amino acid sequences share the highest homology with members of the genus Badnavirus in the family Caulimoviridae. Three ORFs are predicted on the genome-sense strand of the grapevine DNA virus. The nucleotide sequences in the RT and RNase $\mathrm{H}$ region of ORF4 differ from other badnaviruses by $>20 \%$. These differences support the proposition that the newly discovered DNA virus is a distinct species of Badnavirus according to the criteria demarcating species in the genus Badnavirus (10). It is noted, however, that this proposal is based solely on the sequence homology; additional evidence for the presence of bacilliform virions in symptomatic vines will be needed to strengthen the classification. The new virus is provisionally named Grapevine vein clearing virus $(\mathrm{GVCV})$ because it is closely associated with the vein-clearing and vine decline syndrome (Figs. 3 to 5; Table 3).
Two challenging questions to be answered, which are important for preventing spread of GVCV to more grape-production areas, are where GVCV originated and how it is transmitted. We propose three possible scenarios for the emergence of the syndrome. First, GVCV may exist in wild Vitis spp. that are native to Missouri and neighbor states, and is transmitted to cultivated grapevines in commercial vineyards, as postulated for the new emergence of most plant viruses from native wild plants to cultivated relatives (11). Indeed, we detected GVCV in two accessions of wild Vitis spp. (W. Qiu, unpublished data). In addition, the vein-clearing and vine decline syndrome was first and frequently reported in vineyards of Midwest states where wild Vitis spp. grow in vast native habitats near commercial vineyards. Second, GVCV might have been present but remained latent in those source vines that were originally purchased from nurseries. GVCV was detected in six different grape cultivars that are grown in three states (Table 3), indicating that it may originate in different grape cultivars from multiple sources. GVCV can be vertically transmitted from source vines to propagated vines via vegetative propagation and then cause severe symptoms. It is possible that frequent temperature fluctuations in the Midwest region of the United States enhance the virus titer and exacerbate the symptoms. Third, mixed infections of GVCV with other grapevine viruses may enhance the severity of symptoms, because ToRSV, GFLV, and GRSPaV are also found in some grapevines that exhibit the syndrome (16).

The vein-clearing and vine decline syndrome has been frequently observed in Midwest vineyards of the United States in recent years, suggesting that GVCV is slowly spreading horizontally from vine to vine via insect vectors in commercial vineyards. However, it is not clear which mode of transmission has contributed to the increasing incidence of GVCV. Identification of potential vectors that transmit GVCV in vineyards will be crucial to the management of the disease. Mealybugs, whiteflies, or aphids are likely candidates. It is known that badnaviruses are transmitted by mealybugs in the family Pseudococcidae (9). It will be very interesting to know whether mealybugs are possible vectors of transmitting GVCV in vineyards because they are also the vector of Grapevine leaf roll-associated viruses.

Translucent vein-clearing on young leaves and yellowing veins on mature leaves are two distinct diagnostic symptoms associated with GVCV on all grape cultivars observed thus far. However, foliar symptoms change frequently from vein-clearing to chlorotic

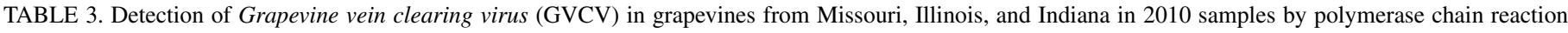
using primer set GVCV-F1 and GVCV-R1

\begin{tabular}{|c|c|c|c|c|c|}
\hline Sample ID & Cultivar & Date of collection & County, state & Vein-clearing symptom & GVCV \\
\hline LBC0901 & Chardonel & 19 June 2010 & Boone, MO & - & - \\
\hline LBC0902 & Chardonel & 19 June 2010 & Boone, MO & + & + \\
\hline LBC0903 & Chardonel & 19 June 2010 & Boone, MO & + & + \\
\hline LBC1001 & Chardonel & 19 June 2010 & Boone, MO & + & + \\
\hline LBC1002 & Chardonel & 19 June 2010 & Boone, MO & - & - \\
\hline LBC1003 & Chardonel & 19 June 2010 & Boone, MO & + & + \\
\hline ILV1001 & Chardonel & 18 June 2010 & Adams, IL & + & + \\
\hline ILV1002 & Chardonel & 17 June 2010 & Pike, IL & + & + \\
\hline ILV1003 & Vidal Blanc & 17 June 2010 & Pike, IL & + & + \\
\hline ILV1004 & Chardonnay & 4 June 2010 & Jackson, IL & + & + \\
\hline ILV1005 & Chardonel & 10 June 2010 & Pike, IL & Not confirmed & - \\
\hline ILV1006 & Chardonel & 10 June 2010 & Pick, IL & Not confirmed & - \\
\hline IDV1001 & Chardonnay & 9 June 2010 & Knox, IN & + & - \\
\hline IDV1002 & Cabernet Franc & 9 June 2010 & Knox, IN & + & + \\
\hline IDV1003 & Cabernet Franc & 9 June 2010 & Knox, IN & + & + \\
\hline IDV1004 & Riesling & 9 June 2010 & Knox, IN & + & + \\
\hline IDV1005 & Riesling & 9 June 2010 & Knox, IN & + & + \\
\hline IDV1006 & Marquis & 9 June 2010 & Knox, IN & + & - \\
\hline IDV1007 & Chardonel & 9 June 2010 & Knox, IN & Not confirmed & + \\
\hline IDV1008 & Corot noir & 9 June 2010 & Knox, IN & Not confirmed & + \\
\hline IDV1009 & Vidal Blanc & 9 June 2010 & Knox, IN & + & - \\
\hline IDV1010 & Melody & 9 June 2010 & Knox, IN & + & - \\
\hline
\end{tabular}


or yellowing veins. Some mature leaves are deformed, roll backward, and show mosaic symptoms. In most cases, very severe foliar symptoms appear on the first few leaves, disappear on the next emerging leaves, and then reappear on new emerging leaves on the same shoot. Furthermore, some foliar symptoms resemble those caused by nepoviruses. Therefore, variations in the spectrum of symptoms easily confound the diagnosis of the disease. As with any other plant disease, it is important to be cautious in extrapolating symptoms to the causal pathogens without fulfilling Koch's postulates. There are three characteristics to be considered in the diagnosis of the vein-clearing and vine decline syndrome: (i) vein-clearing appears on young leaves that emerge from overwinter buds in the early growing season, (ii) GVCV is closely correlated with the translucent vein-clearing symptom, and (iii) vein-clearing may be caused by agents other than GVCV. Whether GVCV is the sole causal pathogen will be answered by the development of an infectious clone of GVCV and its successful inoculation onto susceptible grapevine.

PCR products using genomic DNA as templates were detected only in symptomatic vines but not in asymptomatic vines of the same grape cultivar (Fig. 3B; Table 3). These results demonstrated that GVCV exists as an episomal DNA form in grapevines. Sequences of the GVCV genome were also searched against the sequences of the grapevine reference genome PN40024 (http:// www.genoscope.cns.fr/externe/GenomeBrowser/Vitis/), and did not show any similarity with grapevine reference genome sequences. Bertsch et al. (3) analyzed the whole-genome sequence of $V$. vinifera 'Pinot Noir' and identified the presence of certain pararetrovirus-like sequences in the grapevine genome (3). They hypothesized that grapevines develop resistance to pararetroviruses due to the RNA silencing triggered by these endogenous viral sequences and speculated that pararetroviruses are either extinct or not infectious in grapevines. The results from this study provide strong evidence that a DNA virus is present episomally in grapevines, proving that the above hypothesis is incorrect.

The number of vsRNAs is significantly lower in VFM411 than in LBC0903, because 8 of 27 viruses were not detected in VFM411 (Table 1). Fewer viruses are likely a consequence of the procedure of microshoot tip culturing upon thermotherapy; however, we cannot address the effectiveness of eliminating viruses by this procedure because the virus status of the Chardonel vine for generating the VFM411 vine was not determined before the thermotherapy. Nevertheless, we could conclude that the microshoot tip culture in combination with thermotherapy cannot eliminate all viruses. Our results clearly indicated that there are more viruses infecting a single vine in a commercial vineyard than conventionally speculated. In agreement with these results, Coetzee et al. documented three major grapevine virusesGLRaV-3 (58.3\% of total vsRNA reads), GVA, and GRSPaVand three known viruses from a vineyard sample of pooling 44 randomly selected vines (5). In addition, we detected three grapevine viroids (data not shown), as also reported in a recent study (21). Complex interactions, synergistic or antagonistic among multiple viruses and viroids as well as with influences of grape cultivars, are becoming a norm in commercial vineyards and bring unprecedented challenges to the sustainability of growing grapevines.

\section{ACKNOWLEDGMENTS}

Y. Zhang and K. Singh contributed equally to this work. This research was supported by grants 2006-38901-03542 and 2008-38901-19367 from the United States Department of Agriculture Cooperative State Research, Education and Extension Service. We thank J. Schoelz for providing insightful comments and suggestion to the research and manuscript; J. Schoelz, A. Geering, and M. Odneal for critical reviewing of the manuscript; anonymous owners of commercial vineyards, B. Taylor in the University of South Illinois, and B. Bordelon in Purdue University for providing symptomatic vines; and B. Dalley in the Microarray and Genomic Analysis Core Facility at the University of Utah, Salt Lake City, for technical assistance with construction of sRNA cDNA libraries and deep sequencing. GenBank Accession number JF301669.

\section{LITERATURE CITED}

1. Adams, I. P., Glover, R. H., Monger, W. A., Mumford, R., Jackeviciene, E., Navalinkiene, M., Samuitiene, M., and Boonham, N. 2009. Nextgeneration sequencing and metagenomic analysis: A universal diagnostic tool in plant virology. Mol. Plant Pathol. 10:537-545.

2. Al Rwahnih, M., Daubert, S., Golino, D., and Rowhani, A. 2009. Deep sequencing analysis of RNAs from a grapevine showing Syrah decline symptoms reveals a multiple virus infection that includes a novel virus. Virology 387:395-401.

3. Bertsch, C., Beuve, M., Dolja, V., Wirth, M., Pelsy, F., Herrbach, E., and Lemaire, O. 2009. Retention of the virus-derived sequences in the nuclear genome of grapevine as a potential pathway to virus resistance. Biol. Direct 4:21.

4. Carra, A., Mica, E., Gambino, G., Pindo, M., Moser, C., Pè, M. E., and Schubert, A. 2009. Cloning and characterization of small non-coding RNAs from grape. Plant J. 59:750-763.

5. Coetzee, B., Freeborough, M.-J., Maree, H. J., Celton, J.-M., Rees, D. J. G., and Burger, J. T. 2010. Deep sequencing analysis of viruses infecting grapevines: virome of a vineyard. Virology 400:157-163.

6. Ding, S.-W., and Voinnet, O. 2007. Antiviral immunity directed by small RNAs. Cell 130:413-426.

7. Donaire, L., Wany, Y., Gonzalez-Ibeas, D., Mayer, K. F., Aranda, M. A., and Llave, C. 2009. Deep sequencing of plant viral small RNAs reveals effective and widespread targeting of viral genomes. Virology 392:203214.

8. Fung, R. W. M., Gonzalo, M., Fekete, C., Kovacs, L. G., He, Y., Marsh, E., McIntyre, L. M., Schachtman, D. P., and Qiu, W. P. 2008. Powdery mildew induces defense-oriented reprogramming of the transcriptome in a susceptible but not in a resistant grapevine. Plant Physiol. 146:236-249.

9. Harper, G., Hart, D., Moult, S., and Hull, R. 2004. Banana streak virus is very diverse in Uganda. Virus Res. 100:51-56.

10. Hull, R., Geering, A., Harper, G., Lockhart, B. E., and Schoelz, J. E. 2005. Genus Badnavirus. Pages 392-396 in: Virus Taxonomy: 8th Report of the International Committee for Taxonomy of Viruses. C. M. Fauquet, M. A. Mayo, J. Maniloff, U. Desselberger, and L. A. Ball, eds. Elsevier Academic Press, San Diego, CA.

11. Jones, R. A. C. 2009. Plant virus emergence and evolution: origins, new encounter scenarios, factors driving emergence, effects of changing world conditions, and prospects for control. Virus Res. 141:113-130.

12. Kasschau, K. D., Fahlgren, N., Chapman, E. J., Sullivan, C. M., Cumbie, J. S., Givan, S. A., and Carrington, J. C. 2007. Genome-wide profiling and analysis of Arabidopsis siRNAs. PLoS Biol. 5:e57.

13. Komar, V., Vigne, E., Demangeat, G., Cornuet, P., and Fuchs, M. 2006. Effect of virus combinations on the performance of Vitis vinifera var. Chardonnay. Pages 134-135 in: Extended Abstr. XIV Meet. Int. Counc. Study of Viruses and Virus-like Disease of the Grapevine, Stellenbosch, South Africa.

14. Kreuze, J. F., Perez, A., Untiveros, M., Quispe, D., Fuentes, S., Barker, I., and Simon, R. 2009. Complete viral genome sequence and discovery of novel viruses by deep sequencing of small RNAs: a generic method diagnosis, discovery and sequencing of viruses. Virology 388:1-7.

15. Li, H., Ruan, J., and Durbin, R. 2008. Mapping short DNA sequencing reads and calling variants using mapping quality scores. Genome Res. 18:1851-1858.

16. Lunden, S., Meng, B., Avery, J. D., and Qiu, W. P. 2009. Characterization of a grapevine vein-clearing complex on Chardonnay. Eur. J. Plant Pathol. 126:135-144.

17. Martelli, G. P., and Boudon-Padieu, E. 2006. Directory of infectious diseases of grapevines and viruses and virus-like diseases of the grapevine: Bibliographic report of 1998-2004. In: Options Mediterraneennes, Serie B: N.55. CIHEAM, Bari, Italy.

18. Medberry, S. L., Lockhart, B. E., and Olszewski, N. E. 1990. Properties of Commelina yellow mottle virus's complete DNA sequence, genomic discontinuities and transcript suggest that it is a pararetrovirus. Nucleic Acid Res. 18:5505-5513.

19. Meng, B., Rebelo, A. R., and Fisher, H. 2006. Genetic diversity analyses of grapevine Rupestris stem pitting-associated virus reveal distinct population structures in scion versus rootstock. J. Gen. Virol. 87:1725-1733.

20. Mlotshwa, S., Pruss, G. J., and Vance, V. 2008. Small RNAs in viral infection and host defense. Trends Plant Sci. 13:375-382.

21. Navarro, B., Pantaleo, V., Gisel, A., Moxon, S., Dalmay, T., et al. 2009. Deep sequencing of viroid-derived small RNAs from grapevine provides new insights on the role of RNA silencing in plant-viroid interaction 
PLoS ONE 4. doi: 10.1371/journal.pone.0007686.

22. Prosser, S. W., Goszczynski, D. E., and Meng, B. 2007. Molecular analysis of double-stranded RNAs reveals complex infection of grapevines with multiple viruses. Virus Res. 124:151-159.

23. Qiu, W. P., Avery, J. D., and Lunden, S. 2007. Characterization of a severe virus-like disease in Chardonnay grapevines in Missouri. Plant Health Progress. doi: 10.1094/PHP-2007-1119-01-BR.

24. Rowhani, A., Uyemoto, J. K., Golino, D. A., and Martelli, G. P. 2005. Pathogen testing and certification of Vitis and Prunus species. Annu. Rev. Phytopathol. 43:261-278.
25. Rwahnih, M. A., Daubert, S., Golino, D., and Rowhani, A. 2009. Deep sequencing analysis of RNAs from a grapevine showing syrah decline symptoms reveals a multiple virus infection that includes a novel virus. Virology 387:395-401.

26. Warren, R. L., Sutton, G. G., Jones, S. J., and Holt, R. A. 2007. Assembling millions of short DNA sequences using SSAKE. Bioinformatics 23:500-501.

27. Wu, Q., Luo, Y., Lu, R., Lau, N., Lai, E. C., Li, W.-X., and Ding, S.-W. 2010. Virus discovery by deep sequencing and assembly of virus-derived small silencing RNAs. Proc. Natl. Acad. Sci. USA 107:1606-1611. 